\title{
Yapay sinir ağları ile Marshall stabilite değerinin tahmini
}

\section{Estimation of Marshall stability value with artificial neural networks}

\author{
Recep Koray Kıyıldı 1 ,*
}

\author{
${ }^{1}$ Niğde Ömer Halisdemir Üniversitesi, Mühendislik Fakültesi, İnşaat Mühendisliği Bölümü, 51240, Niğde Türkiye
}

\begin{abstract}
Özet
$\mathrm{Bu}$ makalede, Niğde-Adana otoyolu inşaatında yapılan Marshall stabilite deneylerinden faydalanılmıştır. Karot numune üzerinde yapılan deneylerin sonuçları Yapay Sinir Ağları (YSA) ile modellenmiştir. Asfalt betonu karışımı numunesi üzerinde yapılan Marshall stabilite deneyinde; agrega ağırlığına göre bitüm yüzdesi, karışım içindeki bitümün ağırlıkça yüzdesi, hacim özgül ağırlığı ve boşluk değerlerine bağlı olarak bulunan Marshall stabilite değeri YSA yöntemine göre tahmin edilmiştir. Yapılan eğitim sonucu elde edilen tahmin modeli, önceden ayrilan deney sonuçları ile denetlendiğinde, YSA modelinin tahmin ettiğ Marshall stabilite değerleri ile deneysel olarak elde edilen değerlerin arasında iyi bir ilişkinin olduğu belirlenmiştir.
\end{abstract}

Anahtar kelimeler: Asfalt betonu, Marshall deneyi, Yapay sinir ağları

\section{Giriş}

Günümüzde, yeni yapılan konforlu yollar daha çok ulaşım talebi oluşturmaktadır. Karayolu taşımacılığı diğer sektörleri de tetikleyerek geliştirmekte, en önemli lokomotif faktörlerin başında gelmektedir. Karayolu yapılırken uzun süre hizmet verebilmesi için, günümüz inşaat standartlarına uygun olarak yapılması, güvenli seyahat imkanlarının minimum maliyetle sağlanması çok önemlidir.

Bir ülkenin ekonomik ve sosyal bakımdan gelişmesi karayolu ağının tüm ülkeye yayılmasıyla doğrudan ilişkilidir. Karayolu inşaatı rijit ve esnek üstyapı olmak üzere iki şekilde yapılmaktadır. Ülkemizde esnek üstyapı türü daha yaygın olarak kullanılmaktadır. Esnek üstyapılar tasarımı yapılan üstyapı kalınlığına göre birden çok tabakaları içerebilmektedir. Bunlar içerisinde trafik yüklerine en fazla maruz kalan tabaka kaplama tabakasıdır. Bundan dolayı maruz kalacağ 1 gerilmelere dayanabilmesi için bu tabakanın yüksek Elastisite Modülüne sahip olması son derece önemlidir. Bu sayede alt tabakalara iletilen gerilmeler de azaltılmış olmaktadır.

Yapılacak karayolunun bölge özelliklerini de dikkate alarak projelendirilmesi ve bölge çevresinden elde edilebilecek malzemeler kullanılarak inşa edilmesi daha ekonomik sonuçlar vermektedir. $\mathrm{Bu}$ nedenle üstyap1 dizaynında kullanılacak malzemelerin özelliklerinin çok iyi tespit edilmesi gereklidir.

\begin{abstract}
In this article, Marshall stability tests carried out in NiğdeAdana highway construction site were used. The results of the experiments performed on the core sample were modelled by Artificial Neural Networks (ANN). In Marshall stability test performed on the specimen of asphalt concrete mixture; the Marshall stability values, which are determined by the percentage of bitumen according to the weight of aggregate, the percentage by weight of the bitumen in the mixture, the volume specific gravity and the void values, were estimated by using the ANN method. When the prediction model obtained as a result of the training was inspected with the previously separated experimental results, it was determined that there was a good relationship between the Marshall stability values estimated by the ANN model and the experimentally obtained values
\end{abstract}

Keywords: Asphalt concrete, Marshall test, Artificial neural networks

Karayolu inşaatında kullanılan deneyler zaman alıcı ve maliyeti yüksek deneylerdir. Bunun yanında inşaat sonunda karayolundan karot alınarak yapılan deneylerle üstyapı tahrip edilmekte ve bunun sonucu olarak çeşitli bozulmalar tetiklenebilmektedir. $\mathrm{Bu}$ deneylerin belli karayolu kesimlerinde rutin olarak yapılmasının yanında, yapılacak deneylere hızlı ve kolay çözümler sunan yeni yöntemler üzerinde araştırmalar yapılması son derece önem arz etmektedir.

Dünyada karayolu inşaatının gelişimi ve yeni inşaat tekniklerinin araştırılması halen devam eden bir süreçtir. Bu konuda çok sayıda çalışma yapılmış olup, özellikle sıcak karışım asfalt dizaynı konusunda yapılan temel gelişmelerle ilgili [1-7] çalışmaları sayılabilir. $\mathrm{Bu}$ gelişmelere paralel olarak ülkemizde Karayolları Genel Müdürlüğü (KGM), belediyeler ve üniversiteler tarafindan yapılan çok sayıda çalışma vardır [8-22].

Günümüzde sert optimizasyon teknikleri yerine, yumuşak hesaplama kullanımı ön plana çıkmıştır. YSA bu yaklaşımlardan birini oluşturmaktadır. YSA kullanılarak yeni çözümler geliştirilmektedir. Karayolu inşaatı konusunda, YSA ve bulanık mantık yöntemlerinin kullanılmasıyla çok sayıda yayın yapılmış olup [23-56], gelişen bilgisayar teknolojileri ile bu çözümler her geçen gün daha fazla alanda daha gerçekçi çözümler bizlere sunmaktadır.

\footnotetext{
* Sorumlu yazar / Corresponding author, e-posta / e-mail: rkoray@ohu.edu.tr (R.K. Kıyıldı)

Geliș / Recieved: 22.01.2021 Kabul / Accepted: 22.02.2021 Yayımlanma / Published: 27.07.2021

doi: $10.28948 /$ ngmuh. 866566
} 


\section{Materyal ve metot}

\subsection{Esnek üstyapı karayolu kaplaması}

Karayolu üstyapısı inşaat çeşitlerinden birisi olan esnek üstyapı; bitümlü karışımlardan oluşan çeşitli tabakalar halinde yapılmaktadır. Klasik bir üstyapı kesiti; doğal zemin, alt temel, temel ile bitüm kullanılarak imal edilen binder ve aşınma tabakalarından oluşur. Sonuçta imal edilen esnek üstyapı kaplamasının performansı, tamamen şartname kurallarına uygun malzeme ve inşaat teknikleri kullanımına bağlıdır. En üstte bulunan kaplama tabakası büyük gerilmelere direk temasta olacağından, buraya serilecek malzemenin elastisite modülünün yüksek olması hedeflenir. Karışımdaki agrega miktarı yaklaşık \%92 iken bitüm oranı ise $\% 8$ civarındadır [8]. Kaplama tabakasının çok kalın yapılması taşıyacağı tekrarlı dingil yükü sayısını da artırır. Bu sayede alt tabakalara etkiyen basınç ve kayma gerilme miktarı azalır.

Taşıma gücü zayıf olan zeminlerde temel tabakasının taşıma gücünü artırmak için; çimento, bitüm bağlayıcılı karışım, sıkıştırılmış zemin, dikkatle seçilmiş granüler malzeme kullanılarak zeminin taşıma gücü artırılabilir.

\subsubsection{Marshall stabilite deneyi}

Bitümlü karışım; asfalt malzeme ile granüler malzemenin plentte karıştırılmasıyla elde edilir. Hazırlanan bu karışıma asfalt betonu da denir. Asfalt betonu tasarlanan karışım şartname koşullarını sağlayacak nitelikte hazırlanmalıdır. Bunu içinde kullanılacak malzemelerin nitelikleri iyi etüt edilmeli, tartılar doğru yapılmalı, karışım uygun sıcaklık derecesinde karıştırılmalıdır. Uygun şartlar gerçekleştiğinde elde edilen karıșım serilmeye müsait işlenebilirlikte olmalıdır. Sonrasında uygun taşıma araçlarıyla taşınarak, serme makinesi yardımıla istenilen kalınlıkta serilerek, silindirlerle sıkıştırılır.

Marshall stabilite deneyi, ASTM D 1559 (Marshall deney aletleri ile bitümlü karışımların plastik akmaya karşı direnci) bölümünde yayınlanmıştır [9].

Marshall deney malzemeleri şartname şartlarına göre hazırlanmalıdır. Hazırlanan numuneler $64 \mathrm{~mm}$ yüksekliğinde, $102 \mathrm{~mm}$ çaplı karot şeklindedir. Deney numunelerinin stabilitesi, standart numunenin $60{ }^{\circ} \mathrm{C}$ sicaklıkta sağlayacağı Newton (lb.) biriminde maksimum yük mukavemetidir. Akma değeri, stabilite deneyi boyunca yüksüz ve maksimum yük konumları arasında numunenin göstereceği $0,25 \mathrm{~mm}$. biriminde toplam deformasyondur.

Marshall deneyinin yapılmasındaki amaç karayolunun şartnameye uygun stabilite değerinde inșa edilip edilmediğini belirlemektir. Serim işlemi yapacak olan kamyondan ya da finişer arkasından bitüm agrega karışımı malzemeden numune alınarak sıcaklı̆ğ ölçülür, bu ölçüm $150{ }^{\circ} \mathrm{C}^{\prime}$ den fazla ise deney için uygundur. Laboratuvarda numune kapları $160^{\circ} \mathrm{C}$ lik etüvde bekletilir. Alınan numune silindir kaplara yerleştirilir, yerleştirilen numunenin iyice sıkışması için numune şişlenir ve yüzeyi yuvarlak fitre kağıdıyla kapatılır. Sonra tokmak makinesine numune yerleștirilip, $460 \mathrm{~mm}$ yükseklikten $4550 \mathrm{~kg}$ ağırlı̆̆ıındaki tokmak serbest düşüş uygulayarak numunenin altlı ve üstlü her iki yüzeyine 75 darbe vurulur. Daha sonra numunenin alt ve üst yüzeyindeki fitre kağıtlarını spatula ile sıyırllıp çıkartılır [10-11].

Numune bir gün bekletilir ve daha sonra numune, numune kabından kriko ile çıkartılır. Numunenin havadaki ağırlığ sudan çıkartılır numunenin yüzeyi havlu ile silinerek tartılır ve doygun yüzey ağırlığ ağırlığından sudaki ağırlığı çıkarılarak numunenin hacmi bulunur. Sonra ise numunenin havadaki ağırlığı, hesaplanan hacme bölünerek numunenin özgül ağırlığı bulunur. Su banyosunu $60^{\circ} \mathrm{C}$ ' ye ayarlanır ve numune (biriket) 45 dakika su banyosunda bekletildikten sonra çıkarılıp yüzeyi havlu ile iyice kurulanır. Daha sonra numune kırma makinesine alınır ve kırılır. Biriketin kırıldığı anda ekranda yazan yük değeri stabiliteyi ve iğne ise numunenin akma değerini ölçer. Maksimum yük değeri ve akma değeri okunarak kaydedilir. Burada dikkat edilmesi geren bir nokta da, hazırlanan numunenin su banyosundan alınıp kırma işleminin başlanmasına kadar geçen sürenin 0.5 dakikadan fazla olmamasıdır. Burada 3 ayrı numune alınarak, bu üç numunenin ortalama değeri alınır. Hesaplanan stabilite değerleri düzeltme faktörleri ile çarpılarak düzeltilmiş stabilite değerleri bulunur. Stabilite düzeltme faktörü ise biriket boylarına göre değişir. 63.5 mm' lik bir numunenin düzeltme faktörü 1 olarak kabul edilir, fakat numunenin boyu $63.5 \mathrm{~mm}$ den farklı ise düzeltmeye ihtiyaç vardır. Deney sonuçları bir rapor şeklinde sunulmalıdır. Rapor kısmında; deneye alınan numunenin cinsi, yani karot numune mi kullanıldı, yoksa laboratuvarda sıkıştırılmış numune mi kullanıldı belirtilmelidir. Ayrıca raporda, maksimum yük değeri, stabilite değeri olarak alınır ve gerekirse düzeltme uygulanır. Maksimum yük anındaki deformasyon değeri plastik akma olarak alınır.

Laboratuvar ortamında Marshall deneyinin yapilması durumunda ise Marshall numuneleri ASTM D 1559 da belirtilen standartlara göre hazırlanır. Laboratuvar koşullarında hazırlanan numunelerin her bir yüzeyine 50 darbe uygulanır. Dört farklı şekilde hazırlanan Marshall numuneleri her bir karışıma 1200 gr agrega konularak hazırlanır.

Deneyde önce boş olan numune kabının ağırlığı tartılır. Sonra numune kabına bitüm numunesi yerleştirilir ve bir kez daha tartılır. Daha sonra sıcaklığ $163{ }^{\circ} \mathrm{C}$ olan ve dakikada 56 devir dönebilen etüve numune yerleştirilir. Numune 5 saat boyunca etüvde bekletilir. 5 saat sonunda etüvden çıkartılan numune tartılır. Daha sonra numunenin 5 saat boyunda kaybettiği kütle kaybının yüzdesi hesaplanır. Şartnamelere göre maksimum \%1 kayba izin verilir.

Sıcak karışımlar çok farklı metotlar kullanılarak hazırlanabilmektedirler. Bunlardan en çok tercih edilen karışım metodu olan Marshall sıcak karışım dizayn metodudur. Marshall karışım metodu her boydaki agrega karışımlarından oluşan kaplama karışımlarında uygulanamaz. $\mathrm{Bu}$ metodun uygulanabilmesi için agrega boyunun en fazla $25 \mathrm{~mm}$ olması gerekmektedir.

Marshall sıcak karışım yöntemi, Marshall deney düzeneğiyle silindir şeklindeki numunenin yan yüzeylerine yükleme yaparak plastik akmaya karşı olan direncini ölçme ilkesine dayanmaktadır. Marshall sıcak karışım metodu; sıvı 
petrol asfaltı, asfalt çimentosu, katran veya dane boyutu 25 mm ye kadar olan agregalar için uygulanmaktadır. Bu metot bitümlü karışımların laboratuvar karışım dizaynında uygulanmaktadır. Marshall karışım dizaynında kullanılmak üzere numuneler standartlarda belirtilen koşullarda hazırlanırlar ve maksimum yük ve akma testine tabii tutulurlar. Yoğunluk ve boşluk oranları gibi belirleyici özellikler hazırlanan numuneler üzerinde saptanmalıdır. Marshall metodunda uygulanan deneylerde kullanılan numuneler, başka metotlarla hazırlanmış veya asfalt yoldan alınmış olan bitümlü karot numuneler kullanılarak maksimum akma ve yük değerlerinin bulunması sağlanabilir. Ancak sonuçlar Marshall metodunda bulunan sonuçlardan farklı olabilmektedir. Stabilite değerleri standartlarda verilen düzeltme faktörleri ile çarpılarak düzeltilir [12].

\subsection{Yapay sinir ă̆lart}

Mühendislik dallarında YSA kullanımı giderek yayılmakta ve etkili sonuçların alındığı görülmektedir. Bunlara örnekler verecek olunursa, karayolu kaplama dizaynı, kaplamanın durumunu inceleyerek ne tür bakımların yapılması gerektiğinin planlanması, ulaşım da trafik yoğunluğunun izlenerek yoğunluğun arttığı yönlerdeki yeşil 1şık sürelerinin yeniden ayarlanarak uygulanması, uzun vadeli ulaştırma planlaması tasarlayarak oluşacak talebi taşıma problemlerine çözümler üretilmesi sayılabilir.

YSA eldeki verileri öğrenme mantığıyla çalışan bir sistemdir. Diğer bir deyişle ne kadar çok veri girilirse o kadar doğru sonuçlar bulunmaktadır. YSA öğrendiklerini anımsayarak bilgiler arasındaki en etkili çözümü bulabilme mantığına sahiptir. Bu çalışma mekanizması insan sinir sistemi yapısına benzediği için bu adı almıştır. İnsan vücudunda biyolojik nöronlar vardır. $\mathrm{Bu}$ nöronlar insan vücuduna gelen uyarıları birbirlerine ileterek beyine gönderirler. Burada mantık bu uyarıların en kısa yoldan beyine ulaştırılması ve beynin kararını vererek yapacağı eylemi gerçekleştirmeye yönelik emirleri vermesidir. YSA da buna benzer bir yapıda çalışmaktadır. YSA da yapay nöronlar temel işlemci görevini yürütmektedir. Bir yapay nöronun yapısı sıralayacak olunursa; girdi verileri, ağırlıklar, toplama (aktivasyon) fonksiyonları, transfer fonksiyonları ve çıkış verileri ifade edilebilir. Burada esas olan en hızlı ve doğru öğrenme yapan fonksiyonları içeren algoritmanın bulunması ve bunun uygulanmasıdır.

Şekil 1 de Temel bir YSA nöronun yapısal şeması görülmektedir [23].

Şekil 1 de verilen $X$ verileri $\left(X_{1}, X_{2}, \ldots . X_{n}\right)$ girdi değerleridir. $\mathrm{Bu}$ değerler bağlantılardaki ağırlıklarla $\left(\mathrm{W}_{1 \mathrm{j}}, \mathrm{W}_{2 \mathrm{j}}, \ldots . \mathrm{W}_{\mathrm{nj}}\right)$ hücreye girer. Bir ağırlık değerinin diğer ağırlık değerine göre büyük olması o hattaki girişin sinire daha kuvvetli bağlanması manasına gelmektedir. $\mathrm{Bu}$ veriler toplama fonksiyonundan geçirilerek hücreye giren girdiler hesaplanır.

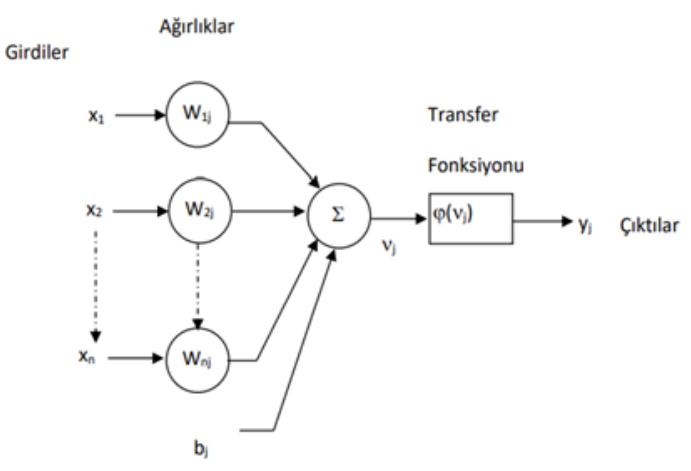

Şekil 1. Temel bir YSA nöronun şeması.

Toplama fonksiyonu gelen her bir ağırlığın ait olduğu girişlerle çarpımının toplamlarına eşik değerinin ilave edilmesiyle bulunur. Elde edilen bulgu transfer fonksiyonundan geçirilerek hücre çıktı değeri bulunur. Burada transfer fonksiyonu devamlı ve türevlenebilir bir şekilde çalışarak eğitimi tamamlar. YSA araştırmasında çok sayıda transfer fonksiyonu kullanmaktadır. Mühendislik problemlerinin çözümünde daha çok tanjant hiperbolik, tanjant sigmoid, doğrusal fonksiyonlarının tercih edilmesiyle hızlı sonuçların alındığı görülmektedir nöronların bir araya gelmesiyle YSA mimarisi oluşmaktadır. Temel bir YSA mimarisinde; giriş tabakası, gizli tabaka ve çıkış tabakası bulunmaktadır.

Asfalt betonu inşaatından alınan bir karot numunenin Marshall stabilite değerinin belirlenmesi birçok parametreyi içermektedir. Bunun yanında deneyi yapan kişinin yetkinliği, laboratuvar aletlerinin uygunluğu ve çevresel etkiler gibi birçok faktör de deney sonuçlarına etki edebilmektedir. Bunu önleyebilmek için belli sayıda alınan örnekler üzerinde deneyler yapılarak hesaplanan ortalama değerin kullanılması, laboratuvar ortamında yapay olarak elde edilen numunenin deney sonuçlarının birtakım düzeltme faktörleriyle düzeltilmesi sayılabilir. Hazırlanan bir YSA modelinde tüm değişkenlerin modele eklenmesi genelde mümkün değildir. Bunun yanında tüm değişkenlerin modele eklenmesi modelin hızlı bir şekilde sonuç vermesi bakımından da uygun değildir. Yapılacak modellemede belli değişkenlerin alınması yeterlidir.

$\mathrm{Bu}$ çalışmada Niğde-Adana otoyolu inşaatında yapılan Marshall stabilite deney sonuçlarından faydalanılmıștır. Rutin olarak her gün dökülen asfalt betonu karışımından belli kilometrelerden alınan 62 adet karot numune üzerinde yapılan deneylerin sonuçları YSA ile modellenmiştir. Geliştirilen modelde, agrega ağırlığına göre bitüm yüzdesi $\left(\mathrm{W}_{\mathrm{a}}\right)$, karışım içindeki bitümün ağırlıç̧a yüzdesi $\left(\mathrm{W}_{\mathrm{b}}\right)$, hacimce özgül ağırlık $\left(D_{p}\right)$ ve boşluk yüzdesi $\left(V_{b}\right)$ girdi verileri olarak alınırken, Marshall deneyi sonuçlarından stabilite değeri $\left(\mathrm{MS}_{\mathrm{d}}\right)$ çıktı verisi olarak alınarak tahmini yaptırılmıştır.

Öncelikle belirlenen girdi değerleri ve çıktı değerleri yapılan deney föylerinden çıkartılarak hazırlanmıştır. 62 deney sonucunun 50 tanesi eğitim amacıyla kullanılmıştır. Kalan 12 tanesi ise yapılan eğitim sonucu geliştirilen modelin test edilerek denetlenmesinde kullanılmıştır. Modellemede kullanılan veriler (Tablo1) verilmiştir. 
YSA modellemesinde çözümlemeler MATLAB programında yapılmıştır. Elde edilen veriler eğitim ve test dosyası olarak hazırlanmıştır. Bu dosyalar normalizasyon uygulanarak programa yüklenmiştir. Yapılan çeşitli denemeler sonucunda en uygun eğitim ve test sonuçlarını veren Şekil 2 'de verilen YSA mimarisi $4 * 15 * 15 * 1$ ağ yapısı seçilerek kullanılmıştır. Modellemeci için esas problem gizli katmandaki nöron sayısının ve transfer fonksiyonunun doğru belirlenmesi sorunudur. Seçilen bu mimaride öğrenme algoritmas1 olarak, sinir ağlarının eğitiminde: scaled conjugate gradient backpropagation (Trainscg) algoritmas ve aktivasyon fonksiyonu olarak da logaritma-sigmoid (logsig $\log$ ) transfer fonksiyonu kullanılmıştır. Seçilen ağ yapıs1 4 girdili, 1. gizli tabakada 15 nöronlu 2. katmanda 15 nöronlu ve 1 çıktılı ağ yapısıdır. Sonuçta eğitim ve test verileri için elde edilen hata karelerinin toplamı (SSE) sırasıyla 0.0301 ve 0.0704 olarak bulunmuştur. Sonuçta yapılan eğitim sonucu elde edilen tahmin modeli, önceden ayrılan deney sonuçları ile denetlendiğinde, YSA modelinin tahmin ettiği Marshall stabilite (MSt) değerleri ile deneysel olarak elde edilen değerlerin arasında iyi bir ilişkinin olduğu tespit edilmiştir.

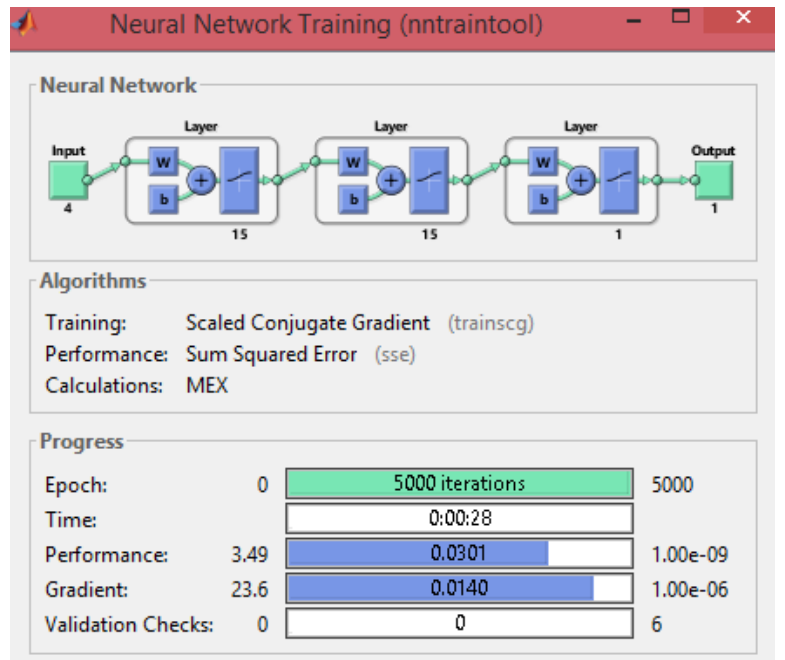

Şekil 2. Çalışmada belirlenen YSA mimari yapısı.

Şekil 2 den de anlaşlacağ 1 gibi4 girdi verisi, 2 gizli tabakada eğitilerek, bir çıktı verisi üretilmiştir. Burada esas konu üretilen çıktının hata güncellemesinin yapılmasıdır. Bir sonraki adımda hata geri yayılarak ağırlıklar yeniden dağıtılarak belirlenmekte ve yeni değerlere göre eğitim tekrar yapılmaktadır. Eğitim sonunda elde edilen sonuç SSE ile sonlandırilır. Burada performans karesel hataların toplamına göre ölçülmektedir. İfadesi Denklem (1) de verilmiştir.

$$
\mathrm{SSE}=\sum_{\mathrm{i}=1}^{m}\left(T_{i}-\text { out }_{i}\right)^{2}
$$

$\mathrm{Bu}$ denklemdeki. SSE; performansı karesel hataların toplamına göre ölçer ve hatadan kaynaklanan karelerin toplamıdır. $T_{i}$ gerçek verilerin ortalaması. out $t_{j}$ gerçek veri değeridir.
Tablo 1. Modellemede kullanılan Marshall deneyi girdi ve çıktı değerleri

\begin{tabular}{|c|c|c|c|c|c|}
\hline $\begin{array}{l}\mathrm{W}_{\mathrm{a}} \\
\%\end{array}$ & $\begin{array}{l}\mathrm{W}_{\mathrm{b}} \\
\%\end{array}$ & $\begin{array}{c}\mathrm{D}_{\mathrm{p}} \\
\mathrm{gr} / \mathrm{cm}^{3}\end{array}$ & $\begin{array}{l}\mathrm{V}_{\mathrm{h}} \\
\%\end{array}$ & $\begin{array}{c}\mathrm{MS}_{\mathrm{d}} \\
\mathrm{kg}\end{array}$ & $\begin{array}{c}\mathrm{MS}_{\mathrm{t}} \\
\mathrm{kg}\end{array}$ \\
\hline 3.82 & 3.68 & 2.429 & 4.51 & 1418 & 1388 \\
\hline 3.91 & 3.76 & 2.399 & 5.54 & 1523 & 1492 \\
\hline 3.92 & 3.77 & 2.407 & 5.24 & 1173 & 1171 \\
\hline 4.02 & 3.87 & 2.408 & 5.07 & 1273 & 1315 \\
\hline 3.84 & 3.7 & 2.419 & 4.86 & 1389 & 1339 \\
\hline 3.93 & 3.78 & 2.39 & 5.91 & 1410 & 1421 \\
\hline 4.08 & 3.92 & 2.414 & 4.74 & 1333 & 1349 \\
\hline 3.75 & 3.61 & 2.407 & 5.46 & 1472 & 1447 \\
\hline 3.8 & 3.66 & 2.546 & 4.71 & 1309 & 1307 \\
\hline 3.73 & 3.59 & 2.43 & 4.58 & 1384 & 1372 \\
\hline 4.02 & 3.87 & 2.427 & 4.31 & 1394 & 1388 \\
\hline 4.03 & 3.88 & 2.413 & 4.84 & 1333 & 1326 \\
\hline 3.8 & 3.66 & 2.426 & 4.66 & 1386 & 1395 \\
\hline 3.82 & 3.68 & 2.417 & 4.99 & 1392 & 1398 \\
\hline 3.91 & 3.76 & 2.413 & 5.01 & 1415 & 1419 \\
\hline 3.84 & 3.7 & 2.393 & 5.89 & 1507 & 1484 \\
\hline 3.84 & 3.69 & 2.412 & 5.16 & 1465 & 1450 \\
\hline 3.85 & 3.71 & 2.383 & 6.28 & 1417 & 1417 \\
\hline 3.86 & 3.72 & 2.421 & 4.77 & 1384 & 1378 \\
\hline 3.81 & 3.67 & 2.403 & 5.54 & 1440 & 1494 \\
\hline 3.89 & 3.75 & 2.412 & 5.07 & 1476 & 1504 \\
\hline 4.03 & 3.88 & 2.407 & 5.07 & 1355 & 1314 \\
\hline 3.81 & 3.66 & 2.418 & 4.95 & 1255 & 1303 \\
\hline 3.94 & 3.79 & 2.412 & 5.01 & 1426 & 1423 \\
\hline 4.11 & 3.95 & 2.415 & 4.67 & 1294 & 1290 \\
\hline 4.09 & 3.93 & 2.427 & 4.22 & 1235 & 1239 \\
\hline 3.79 & 3.65 & 2.382 & 6.4 & 1246 & 1245 \\
\hline 3.76 & 3.63 & 2.425 & 4.73 & 1330 & 1372 \\
\hline 3.85 & 3.71 & 2.419 & 4.88 & 1253 & 1319 \\
\hline 3.75 & 3.61 & 2.422 & 4.9 & 1309 & 1293 \\
\hline 3.95 & 3.8 & 2.431 & 4.26 & 1309 & 1323 \\
\hline 4.04 & 3.88 & 2.406 & 5.1 & 1156 & 1158 \\
\hline 3.89 & 3.74 & 2.427 & 4.51 & 1401 & 1366 \\
\hline 3.89 & 3.75 & 2.42 & 4.76 & 1355 & 1360 \\
\hline 3.78 & 3.64 & 2.425 & 4.74 & 1440 & 1378 \\
\hline 3.8 & 3.66 & 2.411 & 5.25 & 1196 & 1204 \\
\hline 3.68 & 3.55 & 2.422 & 5 & 1380 & 1380 \\
\hline 3.81 & 3.67 & 2.418 & 4.88 & 1410 & 1336 \\
\hline 3.8 & 3.67 & 2.418 & 4.95 & 1461 & 1368 \\
\hline 4.04 & 3.88 & 2.427 & 4.29 & 1427 & 1382 \\
\hline 4.11 & 3.95 & 2.405 & 5.06 & 1306 & 1304 \\
\hline 3.92 & 3.77 & 2.41 & 5.12 & 1332 & 1326 \\
\hline 3.82 & 3.68 & 2.427 & 4.57 & 1273 & 1393 \\
\hline 3.74 & 3.61 & 2.419 & 5 & 1413 & 1405 \\
\hline 4.07 & 3.91 & 2.418 & 4.61 & 1418 & 1388 \\
\hline 4.04 & 3.89 & 2.425 & 4.39 & 1523 & 1492 \\
\hline 3.77 & 3.64 & 2.421 & 4.9 & 1173 & 1171 \\
\hline 3.71 & 3.58 & 2.413 & 5.3 & 1273 & 1315 \\
\hline 3.76 & 3.62 & 2.396 & 5.87 & 1389 & 1339 \\
\hline 3.82 & 3.68 & 2.429 & 4.51 & 1410 & 1421 \\
\hline 3.75 & 3.61 & 2.407 & 5.5 & 1333 & 1349 \\
\hline 3.89 & 3.75 & 2.42 & 4.76 & 1472 & 1447 \\
\hline 4.06 & 3.9 & 2.409 & 4.95 & 1309 & 1307 \\
\hline 3.83 & 3.68 & 2.427 & 4.56 & 1384 & 1372 \\
\hline 3.83 & 3.69 & 2.409 & 5.3 & 1394 & 1388 \\
\hline 3.96 & 3.81 & 2.425 & 4.49 & 1333 & 1326 \\
\hline 4.02 & 3.86 & 2.418 & 4.69 & 1386 & 1395 \\
\hline 4.03 & 3.88 & 2.428 & 4.27 & 1392 & 1398 \\
\hline 3.98 & 3.83 & 2.42 & 4.65 & 1415 & 1419 \\
\hline 4.07 & 3.91 & 2.418 & 4.61 & 1507 & 1484 \\
\hline 4.04 & 3.89 & 2.425 & 4.39 & 1465 & 1450 \\
\hline 4 & 3.84 & 2.421 & 4.78 & 1417 & 1417 \\
\hline
\end{tabular}

\section{Bulgular ve tartışma}

Yapılan eğitim neticesinde bulunan YSA sonuçları ile kontrol amacıyla ayrılan test sonuçları arasındaki ilişkinin 
Şekil 3 de verildiği gibi $\mathrm{R}^{2}=0.91201$ oranında bulunması oldukça anlamlıdır.

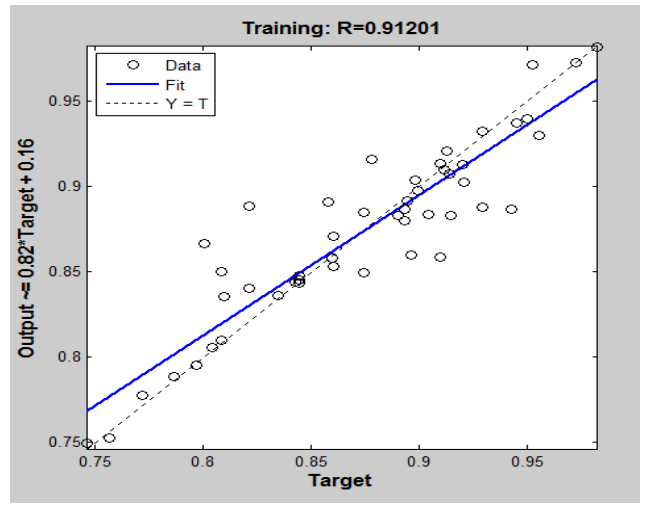

Şekil 3. Çalışmada belirlenen YSA mimarisinin R2 değeri

Şekil 4 de eğitim seti için YSA sonuçlarının gerçek verilerle kıyaslanması diyagramı verilmiştir. Şekil 5 de ise test için ayrılan verilerin gerçek verilerle kıyaslanması diyagramı verilmiştir.

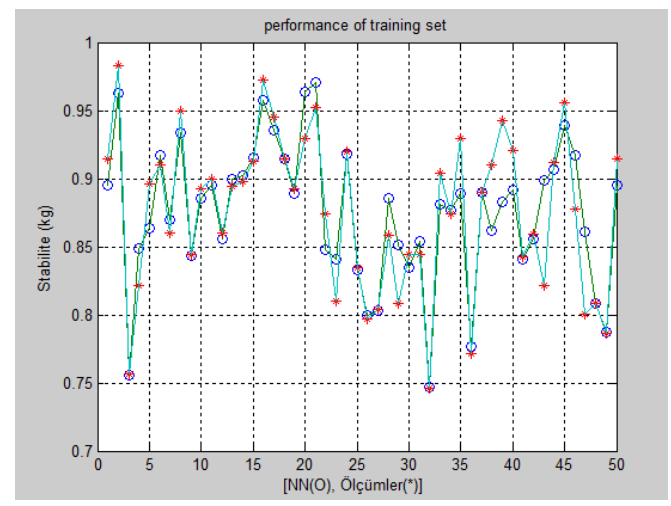

Şekil 4. Çalışmada belirlenen YSA mimarisinde eğitim için ayrılan verilerin YSA sonuçlarının, .gerçek deney sonuçlarıyla karşılaştırılması diyagramı

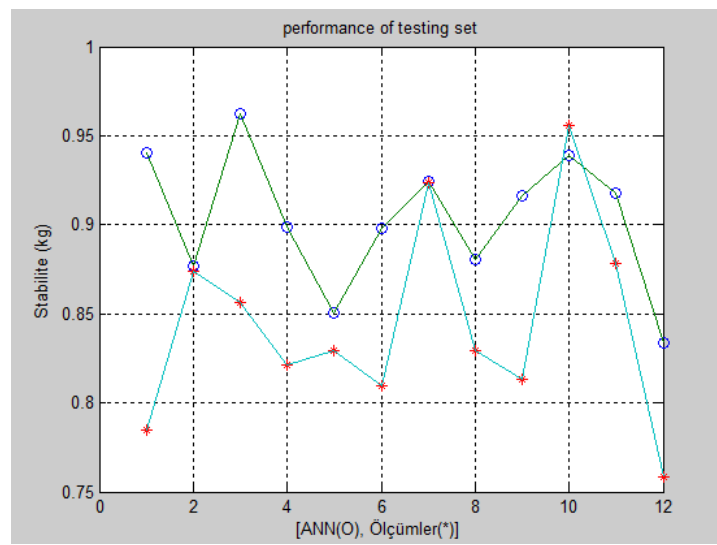

Şekil 5. Çalışmada belirlenen YSA mimarisinde test için ayrılan verilerin YSA sonuçlarının, .gerçek deney sonuçlarıyla karşılaştırılması diyagramı

Normalizasyonu yapılmış analiz sonuçlarının normal veriye dönüştürülmüş durumu Tablo 1 de 6 . Sütunda verilmiş olup, sonuçlar yine aynı tabloda verilen 5 . Sütundaki gerçek Marshall Stabilite değeri ile karşılaştırıldığında oldukça iyidir.

\section{Sonuçlar}

Bu çalışmayla YSA tekniği ile karayolu inşaatında sıkça kullanılan Marshall stabilite değerinin tahmini için bir model ortaya koyulmuştur.

Öncelikle eğitim verileri belirlenen YSA mimarisinde eğitilerek, bir tahmin modeli belirlenmiştir. Bu sonuçlar önceden ayrılan deney sonuçları ile karşılaştırıldığında, YSA modelinin tahmini yaptığ 1 Marshall stabilite değerleri ile deneysel olarak elde edilen gerçek değerler arasında iyi bir ilişkinin olduğu belirlenmiştir. Bu sonuçlar doğrultusunda hazırlanan modelleme yardımı ile, belli sınırlar dahilinde verilen girdi değerlerine göre çıktı değeri hesabı yaptırılabilinir.

Yüksek maliyetlere mal olan karayolu inşaatlarında. konuyla ilgili deneyler ve kalite kontrol yöntemlerinin çabuk ve ucuza yapılması önem arz etmektedir. Sonuçta belli girdilerle elde edilecek çıktının standartlar dahilinde tahmin edilebilmesi maliyetleri azaltıcı bir gelişme olacaktır.

\section{Çıkar çatışması}

Yazar çıkar çatışması olmadığını beyan etmektedir.

Benzerlik oranı (iThenticate): $\% 6$

\section{Kaynaklar}

[1] P. S. Kandhall and R. B. Mallick, Aggregate Tests for Hot Mix Asphalt: State of Practice. NCAT Report No.97-6, 10-15, 1997.

[2] F.L. Roberts, L.N. Mohammad, L.B. Wang, History of hot mix asphalt mixture design in the United States. Journal of Materials in Civil Engineering. 14(4), 279293, 2002. https://doi.org/10.1061/(ASCE)08991561(2002)14:4(279).

[3] P. G. Lavin, Asphalt Pavements. Spon Pres. London and New York, 2003.

[4] The Asphalt Institute. Superpave Mix Design. Superpave Series No.2 (SP-2). U.S.A., 1996.

[5] ASTM D 242, Standard Specification for Mineral Filler for Bituminous Paving Mixtures. Annual Book of ASTM Standards. USA, 1992.

[6] AASHTO T166, Bulk Specific Gravity of Compacted Bituminous Mixtures Using Saturated Surface-Dry Specimens. FHWA Multi-Regional Asphalt Training and Certification Group. 9p., 1999.

[7] AASHTO T209, Bulk Specific Gravity of Bituminous Paving Mixtures. FHWA Multi-Regional Asphalt Training and Certification Group. 5p., 1999.

[8] F. Umar ve E. Ağar, Yol Üstyapısı. İstanbul Teknik Üniversitesi. İnşaat Fakültesi Matbası, İstanbul, 1991.

[9] M. Karasahin, Resilient behaviour of granular materials for analysis of highway pavements. $\mathrm{PhD}$ thesis, University of Nottingham, 1993.

[10] ASTM D1559, Test Method for Resistance of Plastic Flow of Bituminous Mixtures Using Marshall Apparatus, 1998. 
[11] A. Önal ve S. Karaca, Asfalt Betonu Karışım Dizayn Metotları. KGM Yayınları, Ankara, 1990.

[12] M. Önal ve M. Kahramangil, Bitümlü karışımlar laboratuvar el kitabı. KGM Teknik Araştırma Dairesi Başkanlığı, Ankara, 1993.

[13] TS 3720, Bitümlü Kaplama Karışımlarının Hesap Esasları Marshall ve Hubbart Field Metotları. Türk Standartları Enstitüsü, Ankara,1983.

[14] E. Ağar, İ. Sütaş ve G. Öztaş, Beton Yollar (Rijit Yol Üstyapılar1). İTÜ Basımevi, İstanbul, 1998.

[15] A. Tunç, Yol Malzemeleri ve Uygulamaları. Atlas Yayınevi, İstanbul, 2001.

[16] İstanbul Büyükşehir Belediyesi, Asfalt ve Uygulamaları. İSFALT Bilimsel Yayın No:1, İstanbul, 2001.

[17] Yollar Fenni Şartnamesi, Bayındırlık ve İskan Bakanlığı, KGM, 2000.

[18] R. Baş, Superpave: Sıcak Karışım Asfalt Üstyapının Geleceği, Teknik Çeviri, Karayolları 2. Bölge. Müdürlüğü, Asfalt Başmühendisliği, KGM, Ankara, 1999.

[19] H. Varol, Bitümlü sıcak kaplamalı üst yapıların yapım kriterlerinin araştırılması. Yüksek Lisans Tezi, Gazi Üniversitesi Fen Bilimleri Enstitüsü, Ankara, 2000.

[20] M. Ilıcalı, S. Tayfur ve H. Özen, Soğuk karışımlarda agrega gradasyonunun optimum bitüm muhtevasına etkisi. II. Ulusal Asfalt Sempozyumu, 1999.

[21] H. Polat, Ankara Gerede- Ankara Çevre Otoyolu bitümlü karışım üstyapı tabakalarının fiziksel özellikleri ve sıkışabilirliğinin analizi. Yüksek Lisans Tezi, Gazi Üniversitesi Fen Bilimleri Enstitüsü, Türkiye, 1994.

[22] M. Uluçay, Bitümlü Karışımların Tasarımında Yeni Gelişmeler Yoğurmalı Pres. Yollar. Türk Milli Komitesi, Ankara, 1997.

[23] Z. Şen, Yapay Sinir Ağları. Su Vakfı Yayınları, İstanbul, 2004.

[24] J. J. Hopfield, Neural networks and physical systems with emergent collective computational abilities. Proceedings. National Academy of Sciences. 79. National Academy of Sciences. Washington. D. C.. . 2554-2558, $1992 \quad$ https://doi.org/10.1073/pnas. 79.8 .2554

[25] D. E. Rumelhart, G. E. Hinton and J. L. McClelland, A general framework for parallel distributed Processing. in Parallel Distributed Processing: Explorations in the icrostructure of Cognition. I: Foundations. MIT Press. Cambridge. MA. . 45-76. 1986.

[26] P. Mehra and B. W. Wah. Artificial neural networks: concepts and theory. IEEE Computer Society Press. Los Alamitos. CA. 1-8. 1992. https://doi.org/ 10.1109/TMTT.2003.809179

[27] J. J. Hopfield, Neurons with graded response have collective computational properties like those of twostate neurons. Proceedings. National Academy of Sciences. 81. National Academy of Sciences. Washington. D. C.. . 3088-3092. May 1984; https://doi.org/10.1073/pnas.81.10.3088
[28] J. J. Hopfield and D. W. Tank, Computing with neural circuits: A model. Science. 233, 625-633, August 1986. http://doi.org/10.1126/science. 3755256

[29] G. A. Carpenter and S. A. Grossberg, A Massively parallel architecture for a self-organizing neural pattern recognition machine. Computer vision graphics and image processing. 37, 54-115, 1987. https://doi.org/10.1016/S0734-189X(87)80014-2.

[30] G. A. Carpenter and S. Grossberg, ART2: Selforganization of stable category recognition codes for analog input patterns. Applied Optics. 26, 49194930.1987. https://doi.org/10.1364/AO.26.004919

[31] G. A. Carpenter and S. Grossberg, The ART of adaptive pattern recognition by a selforganizing neural network. Computer, March 1988. https://doi.org/10.1109/2.33

[32] R. Hecht-Nielsen. Neurocomputing. Addison-Wesley Publishing Company, New York, 1990.

[33] P. Werbos. Beyond regression: new tools for prediction and analysis in the behavioral sciences. Ph. D. Dissertation, Harvard University, 1974.

[34] D. B. Parker. Learning Logic. Technical Report TR-47. Center for Computational Research in Economics and Management Science, Massachusetts Institute of Technology, Cambridge, MA, 1985.

[35] D. E. Rumelhart, G. E. Hinton and R. J. Williams. Learning representations by backpropagating errors. Nature. 323, 1986, 533-536. https://doi.org/10.1038/ $323533 \mathrm{a} 0$.

[36] J. R. Boyce. A non-linear model for the elastic behaviour of granular materials under repeated loading. Proc. Int. Symp. Soils under Cyclic \& Transient Loading. Swansea. 285-294, 1980.

[37] S. F. Brown and J. W. Pappin, Analysis of pavements with granular bases. Transportation Research Record 810. 17-22, 1981.

[38] S. Ishak, H. Al-Deek. Performance of automatic ANNbased incident detection on freeways. Journal of Transportation Engineering., 125(4). 281-290. 1999. https://doi.org/10.1061/(ASCE)0733947X(1999)125:4 (281)

[39] J. Uzan. Resilient characterization of pavement materials. Int. Journal of Numerical and Analytical Methods in Geomechanics. 16. 453-459. 1. 334-350, 1992. https://doi.org/10.1002/nag.1610160605

[40] J. Uzan, M. W. Witczak. Scullion T \& Lytton RL. Development and validation of realistic pavement response models. Proc. of 7th. Int. Conf. On Asphalt Pavements, 1992.

[41] E. Özgan, T. Kap, A. Beycioğlu ve M. Miroğlu. Asfalt betonunda Marshall stabilitesinin uyarmalı bulanık mantık yaklaşımı ile tahmini. 5. Uluslararası ileri teknolojiler sempozyumu (İATS'09), 2009.

[42] N. Morova, S. Serin, S. Terzi. Bitüm miktarının asfalt betonu dayanımına etkisinin bulanık mantık yaklaşımı ile değerlendirilmesi. 6th International Advanced Technologies Symposium (IATS'11), 2011.

[43] S. Serin, N. Morova, Ş. Sargın, S. Terzi, M. Saltan. The fuzzy logic model for prediction of marshall stability of lightweight asphalt concretes fabricated using 
expanded clay aggregate. SDÜ Fen Bilimleri Enstitüsü Dergisi. 2013. https://doi.org/10.19113/sdufbed.79420

[44] P. Lingras. Classifying highways: hierarchical grouping versus kohonen neural networks. Journal of Transportation Engineering. 121(4), 364-368, 1995.

[45] H. C. Mayhew. Resilient properties of unbound roadbase under repeated triaxial loading. TRRL Laboratory Report 1088, 1983.

[46] J. W. Pappin. Characteristics of a granular material for pavement analysis. $\mathrm{PhD}$ thesis, University of Nottingham, 1979.

[47] J. W. Pappin, SF. Brown. Resilient stress-strain behaviour of a crushed rock. Int. Symp. On Soils and Transient Loading. Swansea. 169-177, 1980.

[48] B. Stackel. The derivation of complex stress-strain relations. Int. Conf. On Soil Mech. and Foun. Eng. Volume 1, Moscow, 353-359, 1973.

[49] J. H. Tsoukalas, ER. Uhrig. Fuzzy and neural approaches in engineering. John Wiley \& Sons. Inc, 1997.

[50] The European Economic Community. A European approach to road pavement design. Progress report 2. 1991.
[51] J. Xu, S. C. Wong., H. Yang and C. O. Tong. Modeling level of urban taxi services using neural network. Journal of Transportation Engineering. 125(3), 216223. 1999.

[52] J. Uzan. Characterization of granular material. Transportation Research Record. 1022. 52-59, 1985.

[53] M. Karasahin, A. R. Dawson and J. T. Holden. The applicability of resilient constitutive models of granular material for unbound base layers. Transportation Research Record. No 1406, 98-107, 1993.

[54] M. Karasahin, A. R. Dawson. Resilient behaviour of cohesionless soil. XII Int. Conf. On Soil Mech. And Foun. Eng.. Delhi. India. 1827-1830, 1994.

[55] M. S. Kaseko, Z. P. Lo, S. G. Ritchie. Comparison of traditional ans neural classifiers for pavement-crack detection. Journal of Transportation Engineering. 120(4), 552-569, 1994. https://doi.org/10.1061/ (ASCE)0733947X(1994)120:4(552)

[56] PV. Lade, R. D. Nelson. Modelling the elastic behavior of granular materials. Int. Journal for Numerical and Analytical Methods in Geomechanics. 2. 521542.1987. 